\title{
The effect of MHD and Brinkman number on laminar mixed convection of newtonian fluid between vertical parallel plates Channel
}

\author{
Ebrahim Salehi \\ Department of Mechanical Engineering \\ Iranian Construction Engineering Organization \\ Mashhad, Iran \\ ebialisina@yahoo.com
}

\author{
Rasul alizadeh,Alireza darvish \\ Department of Mechanical Engineering \\ Quchan Branch Islamic Azad University \\ Quchan, Iran \\ R_alizadeh86@yahoo.com
}

\begin{abstract}
This study investigates MHD and Brinkman number on mixed convection flow in a two parallel-plates vertical channel with reference to laminar, thermal and hydrodynamical developing flow of Newtonian fluid. The boundaries are considered to be isothermal with equal temperatures. The governing equations are solved numerically. Also, their dependence upon certain material parameters have been studied. Velocity, temperature, pressure gradient and Nusselt number profiles have also been presented.
\end{abstract}

Keywords - MHD, Mixed convection, Newtonian fluid, Parallel-plates channel

\section{INTRODUCTION}

Studies of MHD combined forced and free convection heat transfer (mixed convection flow) problem involving Newtonian fluids from vertical channel with constant temperature or constant heat flux boundary condition has attracted considerable attention recently. This interest is due to many important engineering applications which are relevant to this problem. One might come across a flow as such in many industrial applications, such as those in heat exchangers, chemical processing equipment, geothermal reservoirs, cooling the nuclear reactors. As expressed previously, the flow of fluid through channel has been investigated in many engineering applications. One of the earliest analyses on this subject can be found in Tao [1]. Salah El-Din [2] have studied the effect of thermal and mass buoyancy forces on the development of laminar mixed convection between two vertical parallel plates in the case of wall heat and mass fluxes. Rajagopal [3] have done an analytical investigation on free convection for nonNewtonian fluids in a parallel plates channel with different wall temperature. Zibakhsh and Domairry [4] have solved laminar viscous flow in a semi-porous channel by using of homotopy analysis method (HAM). Barletta [5] have studied fully developed mixed convection flow in a parallel plates vertical channel by taking into account the effect of viscous dissipation. In this study the two boundaries are considered as isothermal and kept at equal or at different temperature. Barletta [6] analyzed mixed convection with viscous dissipation in a parallel plate vertical channel with uniform and equal wall temperatures. Barletta [7] have presented an analytica analysis of fully developed mixed convection in vertical channel include power-law fluid reference to unequal and uniform wall temperature boundary condition. Shohel Mahmud et al [8] focused on analyze the first and second law of thermodynamics characteristics of fully developed mixed convection flow in a channel in the presence of heat generation/absorption and transverse hydromagnetic effect with isothermal boundary condition. Krishnan et al [9] experimentally and numerically studied the problem of steady laminar natural convection and surface radiation between three parallel vertical plates, viz., the central heated black plate and two unheated polished side plates, insulated from behind. Lorenzini and Biserni [10] carried out a numerical study based on finite difference method in which a power-law fluid with parabolic inlet velocity profile and constant temperature is considered inside a vertical duct with linearly varying temperature along the channel axis direction.

That the flow is fully developed or other simplicity assumptions like constant pressure gradient and so on are taken into account is mentioned in most of the above reviews. It is evident that one can use such assumption, in ideal case. To exemplify this, it is noteworthy that the fully developed flow can only be established if the channel is very long.

Generally, to date, according to the author's knowledge, there is a lake of information in the literature regarding the flow and heat transfer of thermally and hydrodynamically developing MHD mixed convection of Newtonian fluids through two parallel-plates vertical channel. Therefore, the present work is devoted to study the laminar flow of thermally and hydrodynamically developing MHD mixed convection of Newtonian fluids between two vertical parallel plates channel and also, the influence of different governing parameter on wide range of flow characters was investigated. The graphical results are provided for dimensionless velocity, dimensionless temperature, dimensionless mean temperature, center line pressure gradient and local Nusselt number. 


\section{PROBLEM FoRMULATION}

The MHD vertical and parallel plates channel, as depicted in Fig.(1), consist of two parallel, vertical and electrically insulated plates with an infinite width, a finite distance between them, W, and a finite height, L, maintained at constant and equal temperatures. Within this channel flows a laminar, viscous-incompressible, hydrodynamically and thermally developing and electrically conducting Newtonian fluid, which is submitted to a perpendicular, uniform and constant magnetic field. The medium is assumed to have constant properties, outside of density, for which Boussinesq approximation is assumed to hold good. Beside this, in the energy equation, term representing viscous dissipation is neglected as it is very small and also our aim is study the pure effect of magnetic field on the flow.

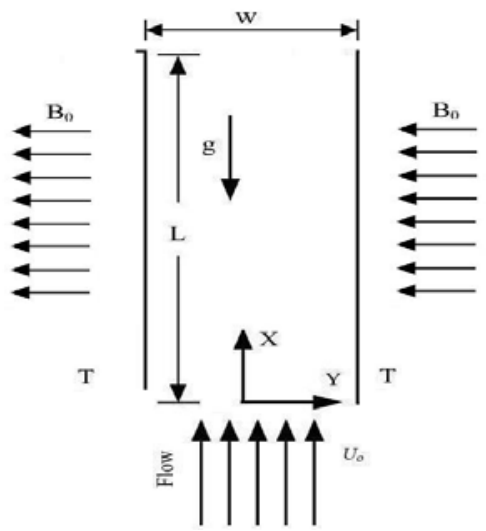

Fig. 1. Geometry and boundary condition

Under the hypothesis above, the governing equations in dimensionless form are:

$\frac{\partial U}{\partial X}+\frac{\partial V}{\partial Y}=0$

$\frac{\partial U}{\partial \tau}+\frac{\partial U^{2}}{\partial X}+\frac{\partial V U}{\partial Y}=-\frac{\partial P}{\partial X}+\frac{1}{\operatorname{Re}}\left(\frac{\partial}{\partial X}\left(-\bar{\mu} \frac{\partial U}{\partial X}\right)+\frac{\partial}{\partial Y}\left(\bar{\mu} \frac{\partial U}{\partial Y}\right)\right)$

$+\frac{G r}{\operatorname{Re}^{2}} \theta-\frac{H a^{2}}{\operatorname{Re}} U$

$\frac{\partial V}{\partial \tau}+\frac{\partial U V}{\partial X}+\frac{\partial V^{2}}{\partial Y}=-\frac{\partial P}{\partial Y}+\frac{1}{\operatorname{Re}}\left(\frac{\partial}{\partial X}\left(\bar{\mu} \frac{\partial V}{\partial X}\right)+\frac{\partial}{\partial Y}\left(\bar{\mu} \frac{\partial V}{\partial Y}\right)\right)$

$\frac{\partial \theta}{\partial \tau}+\frac{\partial U \theta}{\partial X}+\frac{\partial V \theta}{\partial Y}=\frac{1}{\operatorname{Pr} \operatorname{Re}}\left(\frac{\partial^{2} \theta}{\partial X^{2}}+\frac{\partial^{2} \theta}{\partial Y^{2}}\right)^{2}+\frac{B r H a^{2}}{\operatorname{Pr} \operatorname{Re}} U^{2}$

Subjected to boundary conditions:

$X=0,-.5<Y<.5 \Rightarrow\left\{\begin{array}{ll}U=1, V=0 \\ \theta=0\end{array}, \quad Y= \pm .5, X \geq 0 \Rightarrow\left\{\begin{array}{l}U=0 \\ V=0 \\ \theta=1\end{array}\right.\right.$

In the above formulation, the following dimensionless groups were imployed:

$U=\frac{u}{U_{\text {in }}}, \quad V=\frac{v}{U_{\text {in }}}, \tau=\frac{t U_{i n}}{D_{h}} \quad P=\frac{p}{\rho_{0} U_{i n}^{2}}, X=\frac{x}{D_{h}}$
$\theta=\frac{T-T_{0}}{T_{w}-T_{0}}, \quad \operatorname{Pr}=\frac{\mu_{r} C_{p}}{K}, \quad Y=\frac{y}{D_{h}}, \quad \operatorname{Re}=\frac{\rho U_{i n} D_{h}}{\mu_{r}}$

$B r=\frac{\mu_{r} u_{i n}^{2}}{K\left(T_{w}-T_{0}\right)} \quad, \quad H a^{2}=\frac{\sigma B_{0}^{2} D_{h}^{2}}{\mu_{r}} \quad, \quad G r=\frac{g \beta_{T}\left(T_{w}-T_{0}\right)}{U_{i n}^{2}}$

$\mu_{r}=\frac{\mu}{\bar{\mu}}, D_{h}=2 W$

A local Nusselt number can be defined at each boundary, namely:

$$
N u_{D}=\left.\frac{d \theta}{d Y}\right|_{Y=W / 2}
$$

This local Nusselt number is based on, $\theta_{W}-\theta_{0}$, on the other hand, the customary definition of the local Nusselt number is based on balk temperature as the reference fluid temperature, namely:

$$
N u_{T}=N u_{D} \times \frac{T_{w}-T_{0}}{T_{w}-T_{m}}=\frac{N u_{D}}{1-\theta_{b}}
$$

Where $\theta_{b}$ is the dimensionless bulk temperature, which is given by:

$$
\theta_{b}=\frac{\int_{-.5}^{.5} U \theta d Y}{\int_{-.5}^{.5} U d Y}
$$

\section{PROBlEM SOLUTION}

The governing equations are solved by using a finite volume method. The SIMPLE algorithm of Patankar [11] is employed for velocity and pressure coupling. As can be seen, the hydrodynamic flow field which is governed by Eq. (2) is strongly coupled to the thermal flow field, the energy equation, Eq. (4), through the buoyancy term in vertical momentum equation, Eq. (2). So the calculation of energy equation needs to be done sequentially. To solve the system of equations tridiagonal matrix solver is used along width of channel and subsequently the calculation is moved gradually ahead inside the duct.

To fix the grid size with a view to obtain grid independent solutions, a grid independence study was carried out for channel, by comparing velocity, temperature and pressure gradient for different grid sizes. There fore, the calculations with $100 \times 40$ will be considered sufficiently accurate in the present work.

\section{CONCLUSION}

The effect of MHD field on mixed convection of Newtonian fluid flow inside a parallel plates channel is presented in Figs. (2-11). The effect of Hartman number is examined and investigated in different value of Brinkman number. Because of similarity between results only some of them are graphically reported.

The results show increase in the value of Ha number have tendency to slow the movement of the fluid in the centerline of channel and as a result of this, velocity increases near the walls associated with constant flow rate of each section of channel Figs. (2,3). 
Figs. $(4,5)$ illustrates the variation of the pressure gradient with distance at different value of Ha number. It is observed that, while the overall value of pressure gradient increases steadily with $\mathrm{Ha}$, depends on the value of $\mathrm{Br}$ number, it is going toward a constant value, that's mean is the flow is fully developed, in this case, or the pressure gradient is a decreasing function of $\mathrm{X}$. As said before, increase in the value of Ha have a tendency to slow the movement of the fluid in the centerline of channel. This is because of the application of magnetic field, that creates a resistive force similar to the drag force that acts in the opposite direction of the fluid motion, thus casing the maximum velocity of fluid to increase.

Thermal behavior of flow is shown in Figs. (6-11). Overally, the effect of Ha number on thermal behavior of flow can't be explained without association with $\mathrm{Br}$ number. As can be seen in equation (4), this is because of dependency of dissipation term, due to magnetic field to $\mathrm{Br}$ number.

Upon to what said above, at low value of $\mathrm{Br}$ number, magnetic field doesn't have direct and important effect on thermal behavior of flow. Then, as can be seen, there is no significant change in dimensionless temperature profile, beside this, because of changes in velocity, mean temperature and local Nusselt number slightly increase by increase in Hartman number. When Brinkman number increases, magnetic field exerts a significant influence on the flow and there for as $\mathrm{Ha}$ number increases, the magnitude of dimensionless temperature and mean temperature increase contrary to our expectation. While, local Nusselt number except a slight rise, doesn't show any especial changes in it's trend.

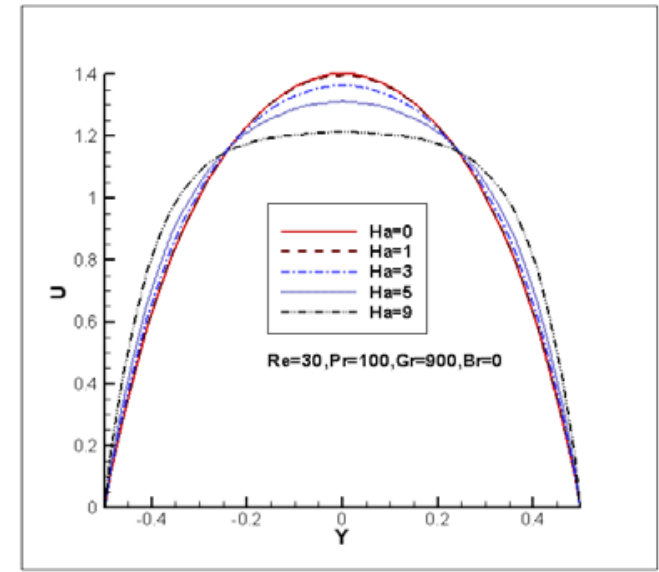

Fig.2. Transient velocity profiles for the different values of Hartman number

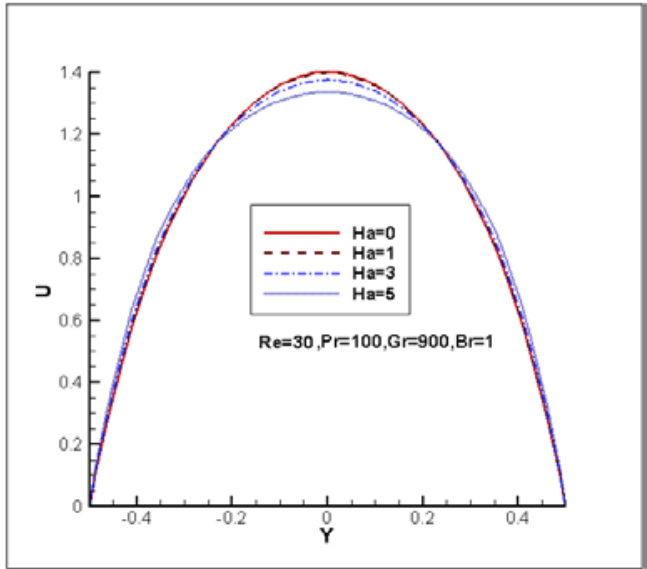

Fig.3. Transient velocity profiles for the different values of Hartman number

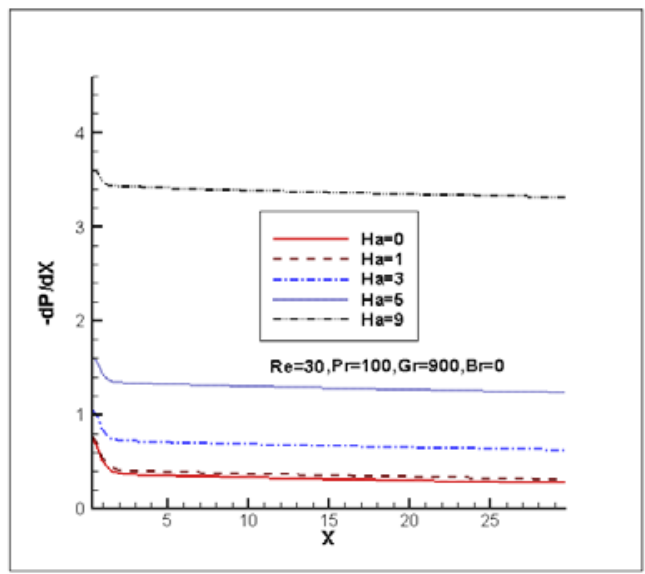

Fig.4. Transient pressure profiles for the different values of Hartman number

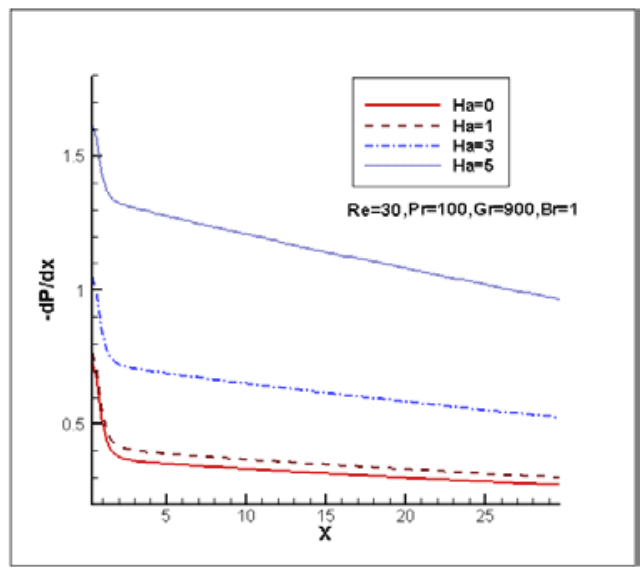

Fig.5. Transient pressure profiles for the different values of Hartman number 


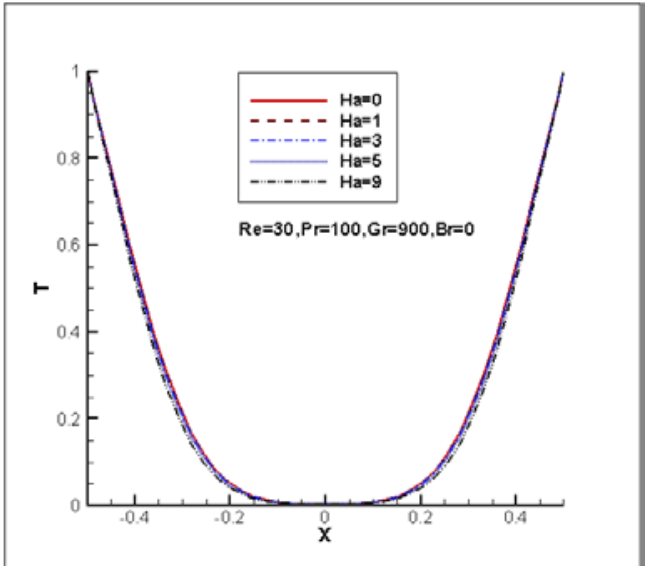

Fig.6. Transient temperature profiles for the different values of Hartman number

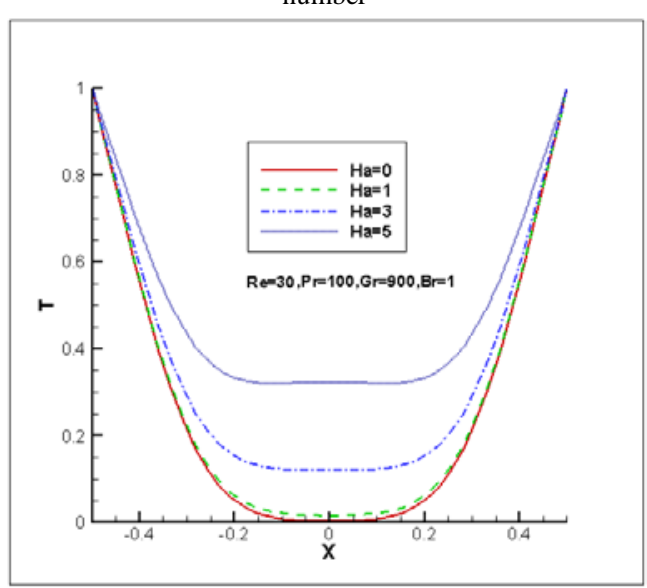

Fig.7. Transient temperature profiles for the different values of Hartman number

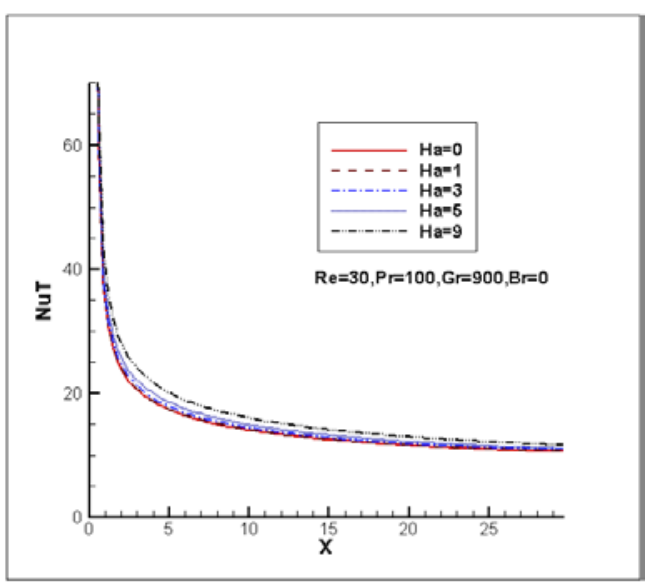

Fig.8. The effect of Hartman number on the local Nusselt number

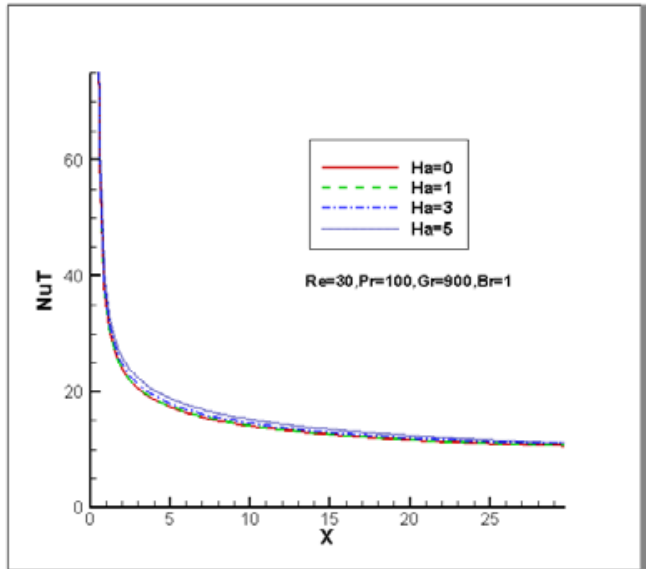

Fig.9. The effect of Hartman number on the local Nusselt number

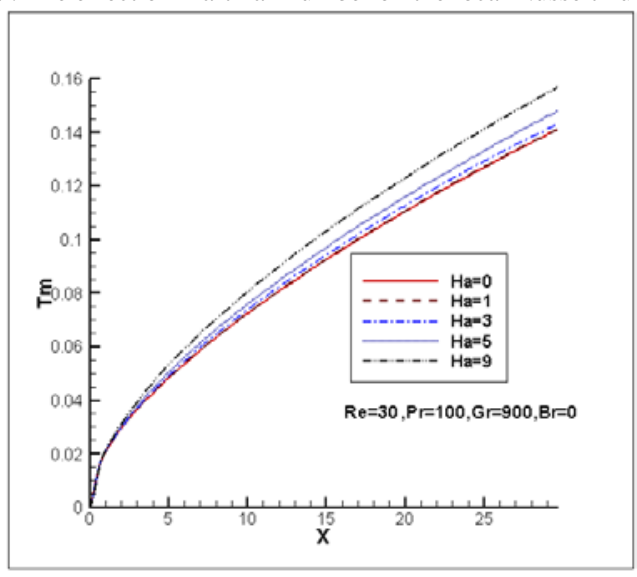

Fig.10. The effect of Hartman number on the mean temperature

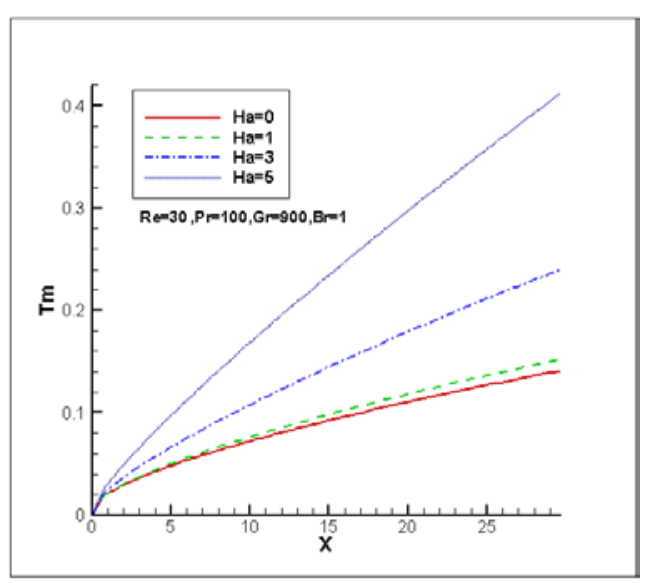

Fig.11. The effect of Hartman number on the mean temperature 


\begin{tabular}{|c|c|}
\hline \multicolumn{2}{|r|}{ Nomenclature } \\
\hline$C_{p}$ & specific heat at constant pressure $\left[J \cdot K g^{-1} \cdot K^{-1}\right]$ \\
\hline$D$ & hydraulic diameter \\
\hline$G r$ & Grashof number \\
\hline$g$ & gravitational acceleration[ $\left.m \cdot s^{-2}\right]$ \\
\hline $\mathrm{Br}$ & Brinkman number \\
\hline $\mathrm{Ha}$ & Hartman number \\
\hline$k$ & Thermal conductivity[ $\left[W \cdot m^{-1} \cdot K^{-1}\right]$ \\
\hline$L$ & Channel height $\left[m_{]}\right.$ \\
\hline$N u_{D}$ & Nusselt number \\
\hline$N u_{T}$ & Nusselt number \\
\hline$P$ & Dimensionless pressure \\
\hline$P$ & Pressure[ $\mathrm{Pa}$ ] \\
\hline $\mathrm{Pr}$ & Prandtl number \\
\hline $\operatorname{Re}$ & Reynolds number \\
\hline$T$ & Temperature[ $K$ ] \\
\hline$t$ & time $\left[{ }^{S}\right]$ \\
\hline$U$ & Dimensionless axial velocity \\
\hline$u$ & Axial velocity \\
\hline$V$ & Dimensionless transverse velocity \\
\hline$v$ & Transverse velocity \\
\hline$W$ & Channel width \\
\hline$X$ & Dimensionless axial coordinate \\
\hline$x$ & Axial coordinate $[m]$ \\
\hline$Y$ & Dimensionless transverse coordinate \\
\hline$y$ & Transverse coordinate $\left[{ }^{m}\right]$ \\
\hline \multicolumn{2}{|r|}{$\begin{array}{c}\text { Greak symbols } \\
\end{array}$} \\
\hline$\alpha$ & Thermal diffusivity $\left[\mathrm{m}^{2} \cdot \mathrm{s}^{-1}\right]$ \\
\hline$\beta$ & Volumetric coefficient of thermal expansion \\
\hline$\mu$ & Dynamic viscosity[ $P$ Pa.s ] \\
\hline$\theta$ & Dimensionless temperaturec \\
\hline$\rho$ & Density[ $\left[g \cdot m^{-3}\right]$ \\
\hline$\tau$ & Dimensionless time \\
\hline
\end{tabular}

\begin{tabular}{|l|l|}
\hline \multicolumn{2}{|c|}{ Subscripts } \\
\hline in & Inlet \\
\hline$m$ & Mean value \\
\hline$O$ & Value at the entrance or reference value \\
\hline$W$ & Value at walls \\
\hline
\end{tabular}

\section{REFERENCES}

[1] Tao LN. On combined free and forced convection in channels. ASME Journal of Heat Transfer 82(1960)233-8.

[2] M.M.Salah El-Din. Effect of thermal and mass buoyancy forces on the development of laminar mixed convection between vertical parallel plates with uniform wall heat and mass fluxes. International Journal of Thermal Science 42(2003)447-453

[3] K.R.Rajagopal, T.Y.Na. Natural convection flow of a non-Newtonoan fluid between two vertical flat plates. Acta Mechanica 54(1985)239-248.

[4] Zibakhsh, Z; Domairry, G.solution of the laminar viscous flow in a semi-porous channel in the presence of a uniform magnetic field by using the homotopy analysis method. Communication Nonlinear Science and Numerical Simulation 14(2009)1284-1294.

[5] Antinio Barletta. Laminar mixed convection with viscous dissipation in a vertical channel. International Journal of Heat and Mass Transfer 41(1998)3501-3513.

[6] A.Barletta. Laminar convection in a vertical channel with viscous dissipation and buoyancy effects. Int. Comm. Heat Mass Transfer 26(1999)153-164.

[7] A.Barletta. On fully developed mixed convection and flow reversal of a power-law fluid in a vertical channel. Int. Comm. Heat Mass Transfer 26(1999)1127-1137.

[8] Shohel Mahmud, Syrda Humaira Tasnim, Mohammad Arif Hasan Mamum. Thermodynamic analysis of mixed convection in a channel with transverse hydromagnetic effect. International Journal of Thermal Sciences 42(2003)731-740

[9] A.K.Krishnan, B.Premachanran, C.Balaji, S.P.Venkateshan. Combined experimental and numerical approaches to multi-mode heat transfer between vertical parallel plates. Experimental Thermal And Fluid Science 29(2004)75-86.

[10] G, Lorenzini, C.biserni. Numerical investigation on mixed convection in a non-Newtonian fluid inside vertical duct. International Journal of Thermal Science 43(2004)1153-1160.

\section{Creative Commons Attribution License 4.0 (Attribution 4.0 International, CC BY 4.0)}

This article is published under the terms of the Creative Commons Attribution License 4.0 https://creativecommons.org/licenses/by/4.0/deed.en_US 